\title{
Professional Use of Social Media by Pharmacists
}

\author{
Arden R Barry and Glen J Pearson
}

\begin{abstract}
Background: A recent trend among health care professionals is the use of social media for professional purposes. These rapidly expanding media allow for timely and efficient access to health information, but they also carry the potential for increased liability. There is a paucity of research detailing how health care professionals, specifically pharmacists, use social media.
\end{abstract}

Objective: To characterize the use of social media by pharmacists in the Canadian province of Alberta and to identify independent determinants of and perceived barriers to using social media for professional purposes.

Methods: Data for this mixed-methods study were collected by an online survey in March and April 2014. Alberta pharmacists were invited to participate via e-mail distributed by 2 professional organizations.

Results: The survey had 273 respondents. Of these, 226 (82.8\%) stated that they had a social media account for either personal or professional purposes, and $138(61.1 \%)$ of these reported using social media for professional purposes, although most respondents used social media predominantly for personal reasons. The most commonly reported social media applications were Facebook and Twitter, accessed primarily via smartphones. Of the 273 respondents, 206 (75.5\%) had a Facebook account, and 101 (49.0\%) of these used Facebook to some extent for professional purposes. Twitter users (104 [38.1\%] of respondents) had a higher rate of professional utilization (57/104 [54.8\%]). The most commonly identified barrier to using social media for professional purposes was concern over liability. Positive predictors of use of social media for professional purposes included younger age and fewer years of professional experience. Participants perceived the most beneficial aspect of social media (in professional terms) as connecting with pharmacist colleagues.

Conclusion: More than $80 \%$ of pharmacists in Alberta reported that they had a social media account, and over half of them reported using their accounts for professional purposes. Although Facebook had a higher reported rate of utilization in general, a greater proportion of respondents reported using Twitter for professional purposes. Individuals and organizations seeking to expand their professional social media presence should focus on Twitter.

Key words: social media, pharmacists, Facebook, Twitter

Can J Hosp Pharm. 2015;68(1):22-7

\section{RÉSUMÉ}

Contexte : L'utilisation des médias sociaux à des fins professionnelles représente l'une des dernières tendances chez les professionnels de la santé. Ces médias en pleine expansion offrent un accès rapide et pratique à de l'information sur la santé, mais ils portent aussi en eux la possibilité d'un accroissement de la responsabilité. Or, les recherches portant sur l'utilisation des médias sociaux par les professionnels de la santé, plus particulièrement les pharmaciens, sont très rares.

Objectif : Caractériser l'utilisation des médias sociaux par les pharmaciens de la province canadienne de l'Alberta et identifier les déterminants indépendants amenant les pharmaciens à utiliser les médias sociaux à des fins professionnelles ainsi que les éléments perçus comme des obstacles à cette utilisation.

Méthodes : Les données de cette étude aux méthodes mixtes ont été recueillies à l'aide d'un sondage en ligne réalisé aux mois de mars et d'avril 2014. Des courriels, envoyés par deux organismes professionnels, invitaient les pharmaciens de l'Alberta à y répondre.

Résultats : L'étude comptait 273 répondants. Parmi ceux-ci, 226 (82,8 \%) ont indiqué qu'ils possèdent un compte de média social; 138 (61,1\%) de ces derniers ont spécifié qu'ils utilisent les médias sociaux à des fins professionnelles, mais la plupart des répondants les emploient principalement pour des raisons personnelles. Les médias sociaux les plus couramment utilisés sont Facebook et Twitter, les répondants y accédant le plus souvent à partir de téléphones intelligents. Parmi les 273 répondants, 206 (75,5 \%) possèdent un compte Facebook et 101 (49,0 \%) d'entre eux l'utilisent à des fins professionnelles. Les abonnés de Twitter (104 personnes au total $[38,1 \%])$ quant à eux sont plus nombreux à l'utiliser dans leur vie professionnelle (57/104 [54,8\%]). Les préoccupations entourant la responsabilité représentent l'élément le plus fréquemment mentionné faisant obstacle à l'utilisation d'un média social à des fins professionnelles. Les facteurs prédictifs de l'utilisation de médias sociaux à des fins professionnelles sont notamment la jeunesse et la courte expérience professionnelle du répondant. Selon les participants, le plus grand avantage de l'utilisation des médias sociaux dans un but professionnel est le rapprochement avec des collègues pharmaciens.

Conclusion : Selon le sondage, plus de $80 \%$ des pharmaciens de l'Alberta possèdent un compte de média social et plus de la moitié d'entre eux l'utilisent à des fins professionnelles. Bien que le sondage montre que Facebook est généralement le plus utilisé, une plus grande proportion des répondants utilisant Twitter ont indiqué qu'ils le font dans un but professionnel. Les personnes et les organismes qui cherchent à accroître leur présence professionnelle sur les médias sociaux devraient ainsi privilégier Twitter.

Mots clés : médias sociaux, pharmaciens, Facebook, Twitter 


\section{INTRODUCTION}

7 he number of social media users has been estimated at over 1.7 billion worldwide and is expected to increase to 2.6 billion by $2017 .{ }^{1}$ Users have a wide variety of motivations for the consideration or increased utilization of social media applications. One recent trend is the use of social media by health care professionals, including pharmacists, for professional purposes. ${ }^{2-6}$ Health care professionals can now access social media to connect with colleagues in their own and other professions, follow professional organizations, and stay informed of the latest medical literature. Several government health regulatory bodies (e.g., Health Canada, US Food and Drug Administration) and prominent medical journals (e.g., the New England Journal of Medicine, The Lancet) now regularly disseminate information via social media platforms.

However, increased access to information carries the potential for increased liability and accountability regarding the content. Any health-related information disseminated by selfidentified health care professionals automatically carries a higher degree of perceived credibility by the public. This situation has led various professional organizations (e.g., the American Society of Health-System Pharmacists [ASHP], the American College of Physicians) to develop policy statements to guide health care professionals who wish to use social media for professional purposes. ${ }^{7,8}$

There is currently a paucity of research evidence detailing how social media are used by health care professionals. The limited research involving pharmacists indicates that although most have at least one social media account, only a small percentage use social media for professional activities. For example, in a survey of pharmacists practising in West Virginia published in 2011, at least three-quarters of participants reported using some type of social media platform; however, only about $10 \%$ used social media, specifically Facebook, for educational purposes and only 16\% used Facebook for professional purposes. ${ }^{9}$ Among pharmacy preceptors at a college of pharmacy in Indiana, 60\% of survey respondents indicated that they used social media, specifically Facebook, but only 16\% used Facebook for professional purposes. ${ }^{10}$ When asked about their willingness to conduct professional activities via social media, about twothirds expressed an interest. More specifically, about half of the respondents stated they would be open to receiving notifications or completing continuing education credits, $40 \%$ would follow professional organizations, and about one-quarter would register for or follow professional meetings. A research group at a college of pharmacy in Florida recently performed a social network analysis of pharmacists on Twitter. ${ }^{11}$ In total, they found more than 600 self-identified pharmacists in the United States who were using Twitter, yet a subgroup analysis determined that only $10 \%$ of their tweets were for professional purposes, mostly to exchange information on health or insurance coverage or to voice job concerns. Finally, in a survey of pharmacy students at 3 pharmacy colleges in the United States, $88 \%$ of respondents reported having a Facebook profile, although their use of this platform for educational or professional purposes was not assessed. ${ }^{12}$

The use of social media for professional purposes among pharmacists in the authors' province remains unknown. This survey study was undertaken to characterize the utilization of social media by pharmacists in the Canadian province of Alberta and to identify independent determinants of and perceived barriers to using social media specifically for professional purposes.

\section{METHODS}

\section{Study Design}

This mixed-methods (quantitative and qualitative) study was based on an online survey administered via SurveyMonkey in March and April 2014. The survey asked specific questions regarding participants' use of social media for both personal and professional purposes (Appendix 1, available at www.cjhponline.ca/index.php/cjhp/issue/view/107/showToc). Participants were also asked about their use of Facebook and Twitter because of the popularity of these platforms in North America.

For this study, the term "social media" was defined for survey respondents as encompassing any Internet-based application that allows for the creation, sharing, or exchange of user-generated information to create a virtual network or community. Using social media for professional purposes was defined as accessing social media where the intent relates directly to the practice of pharmacy or to health care or medicine in general.

The survey was open for a total of 4 weeks. Individuals who completed the survey were deemed to have granted consent (i.e., implied consent). The survey tool was created for the purpose of this study and was evaluated for clarity and completeness through consultation with 3 practising pharmacists at the authors' institution.

Upon completion of the survey, self-identified users of social media for professional purposes were invited to participate in an in-person focus group regarding their use of social media. Informed written consent was obtained from all focus group participants. The primary author (A.R.B.) asked participants 6 open-ended questions about their utilization of social media, its perceived benefits, and potential barriers to its use. All responses were audiorecorded and described by means of a qualitative analysis performed by the primary author. The Health Research Ethics Board at the University of Alberta approved this study.

\section{Study Population}

All practising pharmacists ( $n=4550$ as of December 2013) and pharmacy students in the province of Alberta were eligible to participate in this study. Participants were contacted through 2 pharmacy organizations: Alberta Health Services and the 
Alberta Pharmacists' Association. Alberta Health Services is a publicly funded provincial health authority that employs the majority of hospital-based pharmacists in the province. All pharmacists in this organization were sent a weekly invitation to participate in the study through an e-mail distribution list. The Alberta Pharmacists' Association is a volunteer professional advocacy association primarily composed of community-based pharmacists. Members of the association were invited to participate through a weekly newsletter that was distributed by e-mail. There were no specific exclusion criteria; however, the invitation was not sent to pharmacists who were not members of the aforementioned organizations (because of a lack of feasibility) or to those without access to the Internet or a valid e-mail address on file with 1 of the 2 organizations.

\section{Statistical Analysis}

Descriptive statistics were employed to summarize baseline characteristics and use of social media. A dichotomous univariate analysis ( $\chi^{2}$ test) was used to identify determinants that predicted pharmacists' use of social media for professional purposes. All statistical tests were performed with IBM SPSS Statistics software (version 21, IBM Corporation, Armonk, New York). Any $p$ value less than 0.05 was considered to represent a statistically significant difference.

\section{RESULTS}

Overall, 268 pharmacists and 5 pharmacy students participated in the study, for a total of 273 respondents (about $6 \%$ of practising pharmacists in the province). Participants' baseline characteristics are presented in Table 1. A total of 226 (82.8\%) respondents stated that they had a social media account for either personal or professional purposes. The most common type of social media account was Facebook, followed by Twitter and LinkedIn (Table 2). Participants accessed social media primarily via smartphones (114/225 [50.7\%]), followed by desktop or laptop computers $(72 / 225$ [32.0\%]) and tablets (39/225 [17.3\%]). Of the 226 participants who reported having one or more social media accounts, 138 (61.1\%) indicated that they used social media for professional purposes; however, the majority of these $(114 / 138$ [82.6\%]) indicated that they used social media predominantly for personal reasons, rather than professional reasons (Table 3). Of those who reported using social media for professional purposes, the most common perceived benefit was connecting with pharmacist colleagues. Other popular responses included following professional organizations, staying up to date with the medical literature, and connecting with other health care professionals.

Among perceived barriers to using social media in general, the most commonly reported was a lack of time (106/273 [38.8\%]). In addition, 64 (23.4\%) of all respondents did not perceive a benefit to using social media, and 38 (13.9\%) did not
Table 1. Baseline Characteristics

\begin{tabular}{lc} 
Characteristic & $\begin{array}{c}\text { No (\%) of Respondents } \\
(\boldsymbol{n}=\mathbf{2 6 8})\end{array}$ \\
\hline Age (years) & $66(24.6)$ \\
$20-29$ & $83(31.0)$ \\
$30-39$ & $62(23.1)$ \\
$40-49$ & $50(18.7)$ \\
$50-59$ & $7(2.6)$ \\
$60-69$ & \\
\hline Sex & $210(78.4)$ \\
Women & $58(21.6)$ \\
Men & \\
\hline Experience as a pharmacist (years) & $5(1.9)$ \\
Pharmacy student & $60(22.4)$ \\
0-5 & $49(18.3)$ \\
$6-10$ & $38(14.2)$ \\
11-15 & $28(10.4)$ \\
16-20 & $88(32.8)$ \\
>20 & $146(54.5)$ \\
Primary practice area & $33(12.3)$ \\
Hospital inpatient & $22(8.2)$ \\
Ambulatory clinic & $25(9.3)$ \\
Hospital clinical practice leader & $10(3.7)$ \\
Community pharmacy & $32(11.9)$ \\
Hospital administrator & \\
Other & $180(67.2)$ \\
\hline Highest pharmacy-related education & $50(18.7)$ \\
Bachelor degree & $20(7.5)$ \\
Pharmacy residency & $5(1.9)$ \\
Doctor of pharmacy & $13(4.9)$ \\
Pharmacy student &
\end{tabular}

*Data were missing for 5 respondents.

\section{Table 2. Social Media Accounts*}

\begin{tabular}{lc} 
Type of Social Media & $\begin{array}{c}\text { No. (\%) }+ \text { of Respondents } \\
(\boldsymbol{n}=\mathbf{2 7 3})\end{array}$ \\
\hline Facebook & $205(75.1)$ \\
Twitter & $100(36.6)$ \\
Linkedln & $84(30.8)$ \\
YouTube & $74(27.1)$ \\
Instagram & $64(23.4)$ \\
Blog (e.g., Tumblr, Blogger) & $16(5.9)$ \\
SlideShare & $5(1.8)$ \\
Pinterest & $5(1.8)$ \\
Yammer & $2(0.7)$ \\
No social media accounts & $47(17.2)$ \\
\hline
\end{tabular}

*The data in this table are based on responses to question 2 of the survey. The survey also included specific questions about whether respondents had a Facebook account (question 10) and a Twitter account (question 13); responses to those questions differed slightly $(n=206$ respondents with Facebook and $n=104$ respondents with Twitter).

tThe percentages sum to a value greater than 100 because many respondents reported 2 or more types of social media account. 
Table 3. Nature of Respondents' Use of Social Media

\begin{tabular}{|c|c|}
\hline Type of Use & $\begin{array}{l}\text { No. }(\%) \text { of Respondents } \\
(n=226)\end{array}$ \\
\hline Exclusively personal & 88 (38.9) \\
\hline $\begin{array}{l}\text { Predominantly personal } \\
\text { (limited professional) }\end{array}$ & $114(50.4)$ \\
\hline Equal personal and professional & $12(5.3)$ \\
\hline $\begin{array}{l}\text { Predominantly professional } \\
\text { (limited personal) }\end{array}$ & $8 \quad(3.5)$ \\
\hline Exclusively professional & $4(1.8)$ \\
\hline
\end{tabular}

understand how to use social media. Other concerns that participants identified included keeping their personal and professional lives separate and maintaining their privacy. When asked specifically about barriers to using social media for professional purposes, $130(47.6 \%)$ of the 273 respondents indicated concerns about professional liability or accountability. Furthermore, $97(35.5 \%)$ indicated that they did not perceive a benefit of using social media for professional purposes and $82(30.0 \%)$ reported not having time to do so. Only $10(3.7 \%)$ of respondents were aware of the ASHP Statement on Use of Social Media by Pharmacy Professionals. ${ }^{7}$ Among this group, 7 (70\%) stated that they followed the statement's recommendations most or all of the time. When asked about their intention regarding use of social media for professional purposes in the future, 68 (25.1\%) of 271 respondents to this question indicated that they would continue to use it, $103(38.0 \%)$ indicated that they would not start, and $92(33.9 \%)$ were unsure; only $8(3.0 \%)$ respondents reported that they intended to start using social media for professional purposes upon completion of the survey.
Univariate analysis showed that participants between 20 and 39 years of age and those with no more than 10 years of experience as a pharmacist were more likely to be users of social media for professional purposes (Table 4). Factors that were not significant in this analysis were sex, practice setting, and level of education or training. Notably, all 5 pharmacy students who participated in the survey reported using social media for professional purposes.

Table 5 shows a detailed breakdown of participants' reported use of Facebook and Twitter. The most common reason for using Facebook for professional purposes was to connect with other pharmacists (83/101 [82.2\%]). Users of Twitter for professional purposes reported "following" a variety of individuals and organizations, including professional advocacy organizations (42/57 [73.7\%]), health care organizations (41/57 [71.9\%]), other pharmacists (40/57 [70.2\%]), and medical journals (29/57 [50.9\%]).

Eleven pharmacists who self-reported using social media for professional purposes agreed to participate in the focus group, and $3(27 \%)$ attended the session. The focus group lasted 1 hour. Each of the focus group participants used social media in different ways. One participant used Twitter because of its ease of use and the ability to connect with practitioners around the world. Another participant used LinkedIn and ResearchGate to network with colleagues and to identify practice-based research. The third participant followed the medical literature via Twitter and regional pharmacy-related activities via a pharmacist group on Facebook. The 3 participants estimated that they spent between 15 and 45 minutes daily accessing social media for professional purposes, often during working hours or during their

Table 4. Univariate Analysis of Use of Social Media for Professional Purposes

\begin{tabular}{lccc} 
Variable & \multicolumn{2}{c}{ OR $(95 \%$ CI) } & $p$ Value \\
\hline Age (years): 20-39 versus 40-69 & 2.85 & $(1.73-4.69)$ & $<0.001$ \\
Experience as a pharmacist (years): 0-10 versus $\geq 11$ & 2.63 & $(1.58-4.37)$ & $<0.001$ \\
Female sex & 1.07 & $(0.60-1.92)$ & 0.82 \\
Type of practice: hospital-based* versus other & 0.82 & $(0.45-1.47)$ & 0.50 \\
$\begin{array}{l}\text { Level of education: bachelor's degree versus } \\
\text { higher than bachelor's degree }\end{array}$ & 0.85 & $(0.50-1.43)$ & 0.53 \\
\hline
\end{tabular}

$\mathrm{Cl}=$ confidence interval, $\mathrm{OR}=$ odds ratio.

*Hospital-based practice = inpatient care provider, clinical practice leader, administrator, or ambulatory clinic pharmacist

Table 5. Reported Use of Facebook and Twitter*

\begin{tabular}{lrrrr} 
& \multicolumn{4}{c}{ No. (\%) of Respondents } \\
\cline { 2 - 5 } Type of Use & \multicolumn{3}{c}{ Facebook $(\boldsymbol{n}=\mathbf{2 0 6})$} & \multicolumn{2}{c}{ Twitter $(\boldsymbol{n}=\mathbf{1 0 4})$} \\
\hline Exclusively personal & 105 & $(51.0)$ & 47 & $(45.2)$ \\
Predominantly personal (limited professional) & 95 & $(46.1)$ & 25 & $(24.0)$ \\
Equal personal and professional & 4 & $(1.9)$ & 18 & $(17.3)$ \\
Predominantly professional (limited personal) & 1 & $(0.5)$ & 12 & $(11.5)$ \\
Exclusively professional & 1 & $(0.5)$ & 2 & $(1.9)$ \\
\hline
\end{tabular}

*The data in this table are based on responses to questions 10 and 13 of the survey. 
commute to work. When asked about the most useful aspects of social media for professional purposes, the group identified the following benefits: connecting with colleagues in similar practice areas with whom they would otherwise be unable to connect (e.g., in other countries), having the ability to access the medical literature efficiently and in a timely fashion, and contributing to a broad community of professionals by sharing scholarly activities. With respect to perceptions of the barriers to using social media for professional purposes, focus group participants mentioned inability to understand the functionality and etiquette of Twitter (e.g., re-tweeting, hashtags), inability to access certain resources because of membership-only requirements (e.g., online groups), perceptions about accessing social media for personal reasons during work hours, and concern about accepting statements or opinions from self-identified health care professionals without first reviewing the primary literature.

\section{DISCUSSION}

This survey of a representative sample of pharmacists in the province of Alberta indicated that most had a social media account and over half used social media for professional purposes. However, only $5.3 \%$ of respondents with a social media account (i.e., 12/226) stated that they used social media predominantly or exclusively for professional purposes. This result is likely due to lack of awareness of the utility of social media for professional purposes or concerns about liability. Facebook was the social media platform most commonly reported by participants, yet only half of those with a Facebook account stated that they used it to perform some type of professional activity, and of those, $94.1 \%$ used it predominantly for personal reasons. Twitter, though less commonly used overall, had higher reported use for professional activities. This result is likely due to the ability to access a greater variety of information via Twitter in a concise fashion. Twitter allows users to follow organizations as well as individuals and restricts the amount of information that can be posted at a single time (a practice known as "microblogging"). Of those who reported using Twitter for professional purposes, about one-quarter used it predominantly or exclusively for professional purposes. For Facebook, the majority of professional users did so to connect with pharmacist colleagues, whereas Twitter users followed pharmacy organizations and medical journals in addition to other pharmacists. The most commonly identified barrier to using social media for professional purposes was concern over liability; however, most survey respondents were not aware of the ASHP statement to guide pharmacists about appropriate professional uses of social media. One could speculate that the reason most respondents were not aware of this statement is because so few used social media for professional purposes; also, there is currently no equivalent document for Canadian pharmacists. Despite the information generated by this survey, most respondents indicated no intention of starting to use social media for professional purposes. Unsurprisingly, younger and less experienced pharmacists, as well as pharmacy students, were more likely to use social media for professional activities.

The results of this study indicate relatively high utilization of social media for professional purposes by pharmacists, although most respondents still used social media accounts primarily for personal reasons. Similar to participants in the studies by Alkhateeb and others ${ }^{9}$ and Kukreja and others, ${ }^{10}$ both published in 2011, most pharmacists responding to the survey reported here had a social media account, primarily Facebook. However, the reported utilization of social media for professional purposes was much higher in this study than in the previous studies $(61.1 \%$ versus $16 \%)$. This difference may simply be due to the temporal relationship between the studies, since the use of social media has been expanding rapidly in recent years. In December 2013, Facebook reported 1.2 billion users worldwide, with 757 million active users daily, an increase of $22 \%$ over December 2012. ${ }^{13}$ Similarly, in December 2013, Twitter reported 240 million active users monthly, up $30 \%$ from the previous year. $^{14}$

This study represents one of the largest, most diverse assessments of pharmacists' utilization of social media. However, it had several limitations that warrant discussion. The primary limitation was the low response rate, less than $10 \%$ of practising pharmacists in the province where the study was conducted. However, there is no mechanism more feasible for engaging pharmacists within the province than through advocacy organizations or an individual employer, as was done in this study. There was a risk of selection bias in the study sample, as pharmacists who were not familiar with social media may have been less likely to participate in the survey. Therefore, the rate of pharmacists with a social media account identified by these data may be artificially high. The majority of respondents were practising in a hospital-based setting (211/268 [78.7\%]; see Table 1 ), and as such, the results may not be broadly applicable to pharmacists who practise in the community. Although the health authority that employs hospital-based pharmacists in Alberta does not have a specific policy regarding personal use of social media, it dictates that all access to social media via hospital computers must be in accordance with the acceptable-use policy and that health authority e-mail addresses should not be used to create personal social media accounts. Furthermore, the vast majority of respondents were women (210/268 [78.4\%]; see Table 1), which may limit the applicability of the results. The survey itself was not a validated tool, as it was created for the sole purpose of this study; however, it was independently reviewed for content and clarity by 3 practising pharmacists before it was disseminated. With respect to the focus group, the primary limitations were small sample size and selection bias of the individuals. The small number of participants prevented the 
grouping of responses into themes; therefore, responses for each participant were described. The intention for the focus group was to include self-identified users of social media; however, those who attended the focus group may have been more active users than those who did not attend.

Social media represent a rapidly evolving form of communication that is of perceived value to many health care professionals. These media present an opportunity to advance collaboration, communication, and education among pharmacists and other health care professionals. This study showed that although more pharmacists had Facebook accounts than other types of social media accounts, there was greater utilization of Twitter for professional purposes. On the basis of these data, individuals or organizations seeking to expand their professional presence on social media should probably begin with Twitter as the social media platform of choice. Notwithstanding this suggestion, all health care professionals should be aware of the liability and accountability associated with communicating in a public forum. A few simple principles should be employed to maintain professional integrity and patient confidentiality, such as those outlined in the ASHP statement. ${ }^{7}$ These principles include not posting any disparaging comments or confidential patient information, acting with conscience, and exemplifying a positive role model for students and other health care professionals.

\section{CONCLUSION}

In this survey, $82.8 \%$ of pharmacist respondents reported having a social media account, of which over $60 \%$ were using the accounts for professional activities, primarily to liaise with other pharmacists. On the basis of percent usage, Twitter was the most commonly utilized platform for professional purposes; however, a higher proportion of pharmacist respondents had a Facebook account. Younger pharmacists with less pharmacy experience were more likely to use social media for professional activities.

\section{References}

1. Ahmad I. Global overview of internet, mobile and social media engagement and usage. Haripur (Pakistan): Digital Information World; 2013 Dec 11 [cited 2014 May 29]. Available from: www.digitalinformationworld.com/ 2013/12/social-media-internet-mobile-usage-global-stats-infographic.html

2. O'Hara B, Fox BI, Donahue B. Social media in pharmacy: heeding its call, leveraging its power. J Am Pharm Assoc (2003). 2013;53(6):561-4.

3. DeCamp M. Social media and medical professionalism: toward an expanded program. Arch Intern Med. 2012;172(18):1418-9.

4. Grindrod KA, Gavura S. Pharmacy 2.0. Can Pharm J. 2010;143(3):122-5.

5. Cain J, Romanelli F, Fox B. Pharmacy, social media, and health: opportunity for impact. J Am Pharm Assoc (2003). 2010;50(6):745-51.

6. Mattingly TJ 2nd, Cain J, Fink JL 3rd. Pharmacists on Facebook: online social networking and the profession. J Am Pharm Assoc (2003). 2010;50(3): 424-7.
7. American Society of Health-System Pharmacists. ASHP statement on use of social media by pharmacy professionals. Developed through the ASHP Pharmacy Student Forum and the ASHP Section of Pharmacy Informatics and Technology and approved by the ASHP Board of Directors on April 13, 2012, and by the ASHP House of Delegates on June 10, 2012. Am J Health Syst Pharm. 2012;69(23):2095-7.

8. Farnan JM, Snyder Sulmasy L, Worster BK, Chaudhry HJ, Rhyne JA, Arora VM; American College of Physicians Ethics, Professionalism and Human Rights Committee; American College of Physicians Council of Associates; Federation of State Medical Boards Special Committee on Ethics and Professionalism. Online medical professionalism: patient and public relationships: policy statement from the American College of Physicians and the Federation of State Medical Boards. Ann Intern Med. 2013; 158(8):620-7.

9. Alkhateeb FM, Clauson KA, Latif DA. Pharmacist use of social media. Int J Pharm Pract. 2011;19(2):140-2.

10. Kukreja P, Heck Sheehan A, Riggins J. Use of social media by pharmacy preceptors. Am J Pharm Educ. 2011;75(9):176.

11. Hajar Z, Clauson KA, Jacobs RJ. Analysis of pharmacists' use of Twitter. Am J Health Syst Pharm. 2014;71(8):615-9.

12. Cain J, Scott DR, Akers P. Pharmacy students' Facebook activity and opinions regarding accountability and e-professionalism. Am J Pharm Educ. 2009;73(6):104.

13. Facebook annual report 2013. Menlo Park (CA): Facebook, Inc, Investor Relations; 2013 [cited 2014 May 29]. Available from: http://files. shareholder.com/downloads/AMDA-NJ5DZ/3203893310x0x741493/ EDBA9462-3E5E-4711-B0B4-1DFE9B541222/FB_AR_33501_ FINAL.pdf

14. Twitter annual report 2013. San Francisco (CA): Twitter, Inc, Investor Relations; 2013 [cited 2014 May 29]. Available from: http://files. shareholder.com/downloads/AMDA-2F526X/3202376367x0x742484/ A418947A-E065-4822-8BD4-00FA8EB4E795/Twitter_2013_Annual_ Report___FINAL.pdf

Arden R Barry, BSc, BSc(Pharm), PharmD, ACPR, is a Clinical Practice Leader and Clinical Pharmacist with the Mazankowski Alberta Heart Institute, Pharmacy Services, Alberta Health Services, and a Clinical Academic Colleague with the Faculty of Pharmacy and Pharmaceutica Sciences, University of Alberta, Edmonton, Alberta.

Glen J Pearson, BSC, BSCPhm, PharmD, FCSHP, is a Professor in the Division of Cardiology, Faculty of Medicine and Dentistry, and an Associate Chair with the Health Research Ethics Board (Biomedical and Health Panels), University of Alberta, and is Co-director of the Cardiac Transplant Clinic, Mazankowski Alberta Heart Institute, Edmonton, Alberta. He is also an Associate Editor with the CJHP.

\section{Competing interests: None declared.}

\section{Address correspondence to:}

Dr Arden R Barry

Pharmacy Services, Alberta Health Services

University of Alberta Hospital

0G1.01 WMC

8440 - 112 Street NW

Edmonton $A B$ T6G 2B7

e-mail: arden.barry@ualberta.ca

Twitter: @ArdenBarry 